\title{
3-D OIL SPILL MODELLING. NATURAL DISPERSION AND THE SPREADING OF OIL-WATER EMULSIONS IN THE WATER COLUMN
}

\author{
I. PAPADIMITRAKIS ${ }^{1, *}$ \\ M. PSALTAKI ${ }^{2}$ \\ N. MARKATOS ${ }^{2}$
}

\author{
National Technical University of Athens \\ ${ }^{1}$ School of Civil Engineering \\ ${ }^{2}$ School of Chemical Engineering \\ 5, Heroon Polytechniou St, Zografos 15780, Athens, Greece
}

Received: 04/05/10

Accepted: 29/07/11 *to whom all correspondence should be addressed: e-mail: ypapadim@central.ntua.gr

\section{ABSTRACT}

A 3-D hybrid turbulence model, simulating the transport and fate of oil spills in various waters, is used to evaluate the influence of natural dispersion on the spreading of water-in-oil emulsions formed in the water column. The model combines the Navier-Stokes equations for two-phase flows, the RNG k- $\varepsilon$ submodel, and parameterized expressions of the basic processes affecting the fate of oil spills. The model also considers the presence of waves, the wind- and wave- induced surface drifts, and the influence of surface wave breaking on the oil spills.

Using a stochastic probability model of breaking waves, the loss of surface wave energy into turbulence, due to breaking, is derived and the rate of natural dispersion of oil mass and that of oilwater emulsions formed in the water column is evaluated, under a variety of sea state conditions.

Results in the form of oil concentration profiles with depth, graphs showing the variation of the fraction of water (mass) absorbed by the dispersed oil, at various depths and times, as well as graphs showing the oil mass balance, at the sea surface, at various times are compared with counterpart profiles, and graphs obtained from the literature, and useful conclusions are drawn.

KEYWORDS: Oil spills, oil dispersion, oil-water emulsions, wave breaking, oil spill modelling.

\section{INTRODUCTION}

Problems caused by oil pollution, in either deep or coastal waters, have existed for many years, but they have become particularly urgent recently due to the discovery and exploitation of new, rich deposits of oil on the continental shelf of various countries. As the crude oil is transported across the sea by ships or pipelines, there is always a risk of spillage and the potential to cause significant pollution to the marine environment. Since it is impossible to completely stop such accidental spills, reliable methods for the prediction of transport and weathering of oil spills, at sea, should be elaborated in order to implement rapid-decision methods that would depend on the feasibility and effectiveness of counter measures for preventing large-scale disasters resulting from such accidents.

Once an oil spill has occurred, many processes weather the oil discharged on the sea surface, most of which are controlled by the properties of the spilled oil. Such processes are the evaporation, emulsification, dissolution, photolysis and biodegradation. It is also true that different weathering (or fate) processes dominate at different times, after the spill has occurred, that lead to a loss of oil mass (Spaulding, 1995; 1988). Thus, evaporation, dispersion, and emulsification are important initially, while photolysis, tar-ball formation, sinking and biodegradation become important later. In addition, the relative effect of photolysis and biodegradation, on the mass balance, is small in comparison with that of evaporation, dispersion and emulsification.

Besides the oil properties, environmental conditions, as, for example, winds, waves, currents, water turbulence, salinity, water temperature and solar insulation, are also important and necessary to 
know, for adequately estimating the transport and fate of oil at sea. An overview of the recent approaches used, in numerical models of oil spills in the marine environment, has been given by Reed et al. (1999).

One of the (key) issues of concern in oil spill modeling (efforts) is associated with the description, in a simple yet quantitatively accurate way, of oil droplet formation, (their) size distribution and (their) dynamical behavior in the water column. Oil mixing, near the sea surface, is determined by several processes, (and) most notably by the breaking of surface waves. Turbulent diffusion and dispersion affect greatly oil mixing, and are by themselves enhanced by wave breaking. Dispersion maybe seen as the result of either the shear character of current profiles (in the horizontal and/or vertical direction) or that of surface wave breaking. In the latter case dispersion is characterized as "natural", in contrast to the "shear or hydrodynamic" dispersion. In high sea states, where a slick is subject to turbulence generated by wind shear and breaking waves, the oil is rapidly dispersed vertically in the form of small (i.e., 0.01 to $1 \mathrm{~mm}$ diameter) drops which move in the subsurface layer region. The droplet size, the droplet buoyancy, and turbulence intensity (in the water column) determine the stability of natural dispersion. Unstable droplets, with positive (upwards) buoyancy, resurface gradually.

Surface wave breaking is a complex process and the fluid mechanics of oil "natural" dispersion caused by the former process is not well understood. The interested reader may consult Papadimitrakis (2005) and/or Tkalich and Chan (2002), for a description of wave breaking and other related issues.

Following Tkalich and Chan (2002), we identify the oil mixing layer depth, $z_{m}$, as the height beneath the slick where the oil droplets, generated by the tearing apart of a single slick into smaller pieces by the breaking waves, are uniformly mixed with water. Breaking waves propel the teared oil surface slick into the mixing layer and form a "shower" of (oil) droplets. This "oil" mixing layer should not be confused with the conventionally defined mixing (or mixed) layer encountered near the surface of the sea and of other water bodies. Most of the large( $r$ ) droplets rise back to the slick and coalesce there, whereas smaller droplets may become permanently dispersed in the lower layers of the water column. Below the oil mixing layer, the vertical distribution of the droplets is governed by the subsurface advection and turbulent diffusion. This picture guarantees that the process of oil transport in the sea is essentially 3-D, as indeed has been confirmed by the in situ measurements of Gender (1988), and similar data of other investigators that have detected oil at the depth of $20 \mathrm{~m}$. In the presence of a spectrum of waves, the thickness of oil mixing layer is related to the significant wave height, $\mathrm{H}_{\mathrm{s}}$, and is usually taken as a multiple of the latter, where the multiplication factor $(\approx 1.2-1.6)$ has been found to depend on the sea state (Delvinge and Sweeney, 1988; Li and Garret, 1998).

Estimation of the oil mass, dispersed (mainly) "naturally" in the sea water column, is necessary for appraising the life duration of the spilled oil. The rate of "natural" dispersion depends on the sea state, as well as on the oil slick features (thickness and physical properties).

Oil emulsification, on the other hand, is a process that lowers (or diminishes) "natural" dispersion due to the increase of viscosity, caused by the absorption of water, and the formation of stable water-in-oil emulsions that may contain up to $80 \%$ water. Thus, emulsification causes an increase in the slick thickness which results in both a decrease of the oil spreading rate and an increase of the oil volume, factors that in turn limit the effectiveness of "natural" dispersion to spread the oil in the water column. Hence, "natural" dispersion and emulsification become competitive processes in the sense that each of them causes a rate reduction to the other.

Work on oil spill "natural" dispersion has been done by various investigators, most notably by Delvinge and Sweeney (1988), Reed et al. (1989), Korotenko et al. (2000), Papadimitrakis and Psaltaki (2002), Brovchenko et al. (2003), Tkalich (2006), and perhaps some others. In nearly all of the above references, and in various simulation models of oil slick behavior at sea, use is made of an empirical expression proposed by Delvinge and Sweeney (1988) for the rate of oil mass dispersion in the water column, per unit surface area, caused by the breaking of surface waves. That relationship is, mainly, characterized by its dependence on the oil type, the energy of breaking waves lost into turbulence, and the fraction of sea surface covered by whitecaps, per unit time; the latter (two) quantities are estimated empirically. Thus, it was felt appropriate to reevaluate the magnitude of "natural" dispersion (as used in the literature) by focusing our attention to a more 
precise (theoretical) estimate of both the wave energy converted into turbulence, due to breaking of surface waves, and of the fraction of sea surface covered by the subsequently generated whitecaps.

Evaluation of "natural: dispersion is also useful for estimating the spreading of oil-in-water and waterin-oil emulsions formed, in the water column. In previous studies, Papadimitrakis et al. $(2005 ; 2006)$ presented, in detail, a 3-D hybrid turbulence model for simulating the fate of (hypothetical) oil spills in various waters. Their model combines, in three modules, the Navier-Stokes equations for two-phase flows, following an Eulerian approach, the RNG k- $\varepsilon$ turbulence sub-model, and parameterized expressions of the basic processes affecting the fate of oil spills. The simulated processes include: spreading, advection, evaporation, turbulent diffusion, shear dispersion, natural dispersion, dissolution, emulsification and photo-oxidation; they are described in detail in the above references. The phases involved are the water and oil (and, in some sense as a third phase, the water-in-oil emulsion); they are considered to behave as "interpenetrating continua", that is the phases occupy the same space (although not necessarily at the same time), their share of space being measured by their volume fractions $\mathrm{R}_{\mathrm{i}}$ (for which $\sum_{1}^{2} R_{i}=1$ ). The fractions $\mathrm{R}_{1}$ and $\mathrm{R}_{2}$ correspond to water and oil, respectively. The model predicts the position of the center of mass and the shape of the oil spill in time, as the latter spreads under the action of various forces - and of turbulence diffusion and hydrodynamic dispersion in particular - and then disperses into the water column, mainly, by "natural" dispersion while advected by the wind- and wave-induced or other currents. The wind- and wave-induced drift currents at the sea surface are estimated with the aid of empirical expressions incorporated in the transport module of the model. The model also handles the presence of waves at the sea surface, the enhanced turbulent diffusion caused by surface wave breaking, and the impact of the latter on the dispersion of oil in the water column, by adding source terms in the momentum and T.K.E. equations. The interested reader may also consult the Ph.D. Dissertation of the second author of this work. Due to the limited space available, further elaboration and detailing on that model will be avoided and, again, our attention will focus on oil "natural" dispersion issues and other related matters.

In this study, we use a stochastic probability model of breaking waves for deriving the loss of surface wave energy into turbulence, due to breaking, and the fraction of sea surface covered by whitecaps (all per unit surface area and time). The derived quantities are combined with the pertinent expressions of Delvinge and Sweeney (1988) in order to re-evaluate the rates of "natural" dispersion of oil mass and that of oil-in water emulsions (formed in the water column), under a variety of sea state conditions; the latter are characterized by the wave age and the significant slope of the wave field (a measure of local wave field steepness). Section two of this article provides, briefly, in two sub-sections a description of the "natural" dispersion process, and the associated oil flux rates dispersed into the water column by surface wave breaking, and the process of water-in-oil emulsification. Section three describes briefly the stochastic probability model used to estimate the fraction $\widetilde{\omega}$ of wave energy lost into turbulence (by breaking) and the associated whitecap coverage, $F_{w c}$, whereas section four provides some results. Finally, section five discusses the results and gives, briefly, a summary of the most important conclusions.

\section{OIL "NATURAL" DISPERSION AND EMULSIFICATION}

\subsection{Oil-in-water phase}

Natural dispersion results from the breaking of surface waves "entraining" oil in the water column, vertically. The simplest approach describing this process is based on tabulation of dispersion as a function of sea state and time after oil release (Spaulding et al., 1988). It is expected that the dispersion rate is a function of the slick thickness, the oil-water interfacial tension, the oil density and viscosity, the sea state and, particularly, the fraction of sea covered by breaking waves. The (volume) concentration $\mathrm{C}_{\mathrm{d}}$ of oil droplets, in the water, with diameter $\mathrm{d}$ is described by the following equation (Tkalich and Chan, 2002):

$$
\frac{\partial C_{d}}{\partial t}+\vec{\nabla}\left(C_{d} \vec{u}\right)=Q_{d}^{(\text {dis })}+Q_{d}^{(\text {sed })}
$$


Here $\vec{u}\left(=u_{w}, v_{w}, w^{\prime}\right)$ is the current advective velocity vector whose vertical component includes the influence of oil, present in the water column, vis.: $w^{\prime}=w_{w}+w_{d} ; w_{d}$ is the velocity of oil droplets due to buoyancy. The advective velocities $u_{w}, v_{w}, w_{w}$ include the wind- and wave-induced drifts, that can be expressed in terms of the wind speed $U_{w}$, the wave age and the significant slope of the wave field, plus the current resulting from the solution of hydrodynamic equations.

The dispersion flux $Q_{d}^{(d i s)}$ (in $\mathrm{kg} \mathrm{m}^{-2} \mathrm{~s}^{-1}$ ), associated with the oil particles having diameters in the interval $d-\Delta d / 2$ and $d+\Delta d / 2$ (where $\Delta d$ is of unit size), is defined as the dispersed mass of oil in the water column, per unit surface area and breaking event. It is assumed to be uniformly distributed over the oil mixing depth $\mathrm{z}_{\mathrm{m}} \approx 1.5 \mathrm{H}_{\mathrm{s}}$ (here $\alpha=1.5$ - see Brovchenco et al., 2003). According to Delvinge and Sweeney (1988), the flux of oil droplets of diameter $\mathrm{d}, Q_{d}^{(\mathrm{dis})}$, is given as:

$Q_{d}^{(d i s)}=C(0) \cdot F_{w c} D_{b a}^{0.57} d^{0.7}$

where $F_{w c}$ is the fraction of sea surface covered by whitecaps per average wave period, $D_{b a}$ is the average wave energy dissipated by breaking, per unit surface area (e.g., $\mathrm{J} \mathrm{m}^{-2}$ ), and $\mathrm{C}(0)$ is an empirical constant dependent on the oil viscosity, $\mu$, at temperature $\mathrm{T}_{\text {oil }}\left({ }^{\circ} \mathrm{K}\right)$, vis.: $\mathrm{C}(0) \approx\left[\mu\left(T_{\text {oil }}\right)\right]^{-1}$. $F_{w c}$ and $D_{b a}$, in Eq. (2), are computed with the aid of the following empirical expressions: $F_{w c}=c_{b}\left(U_{w}\right.$ $-U_{w i} / T_{0}$, where $U_{w}$ is the local wind speed measured at the height of $10 \mathrm{~m}$ above MWL, $U_{w i}$ represents a wind speed necessary for the "initiation" of breaking $\left(\approx 5 \mathrm{~m} \mathrm{~s}^{-1}\right), \mathrm{T}_{\mathrm{o}}$ is a characteristic wave period, and $c_{b}\left(\approx 0.032 \mathrm{~s} \mathrm{~m}^{-1}\right)$ is a constant; $D_{b a}=0.0034 \rho_{w} g H_{r m s}^{2}, \rho_{w}$ is the water density and $\mathrm{g}$ is the gravitational acceleration, $H_{r m s}=H_{S} / \sqrt{2}, H_{S}=4 \sqrt{m_{O}}, T_{O}=2 \pi / \sigma_{o}, \sigma_{o}=\left(m_{2} / m_{o}\right)^{1 / 2}$ and $m_{i} \quad(i=0,2$, etc.) is the conventional $i^{\text {th }}$ spectral moment of sea waves, defined in terms of the 1-D sea spectrum (Papadimitrakis and Psaltaki, 2002); $m_{0}$ represents the sea surface variance. Combining the above expressions for $D_{b a}, H_{r m s}$ and $H_{s}$ yields: $D_{b a}=0.027 \rho_{w} g m_{o}$. $D_{b a}$ is also related to both $m_{o}$ and the fraction $\widetilde{\omega}$ (of the wave energy lost into turbulence by breaking, per unit surface area and wave period), through the following relationship: $D_{b a}=\rho_{w} g_{0} \widetilde{\omega}$. It is, thus, apparent that the ratio of analytic and empirical $D_{\text {ba }}$ expressions (i.e., $D_{b e}^{a} / D_{b e}^{e}=36.765 \widetilde{\omega}$ ) is a function of $\widetilde{\omega}$.

$Q_{d}^{(\text {sed })}$, in Eq. (1), represents the flux of oil droplets of diameter d dispersed in the water column and adhered (by scavenging) to the sediments and/or other particulate matter. According to Brovchenco et al. (2003), the flux of oil droplets to sediments having diameter d (in the interval $\Delta \mathrm{d}$ around d), $Q_{d}^{(s e d)}$, is given by the following expression:

$Q_{d}^{(\text {sed })}=-1.3 a^{\prime}\left(\varepsilon / v_{w}\right)^{1 / 2} C_{d} S$

where $\alpha^{\prime}$ is a sticky coefficient and $\mathrm{S}$ is the (volume) concentration of suspended sediments. The latter parameter may be specified externally or determined by another equation describing the sediment balance in the water column. Eq. (1) may be solved now to provide $C_{d}(d)$, throughout the depth, given the current advective velocities $\vec{u}$ and the source terms $Q_{d}^{(\text {dis })}$ and $Q_{d}^{(\text {sed })}$.

The total oil droplet flux consisting of the original surface oil, $Q^{(\text {dis })}$, is given by:

$Q^{(\text {dis })}=\int_{d_{\min }}^{d_{\max }} Q_{d}^{(d i s)} \delta d \approx C(0) \cdot F_{w c} D_{b a}^{0.57}\left(d_{\max }^{1.7}-d_{\min }^{1.7}\right)$

$d_{\min }, d_{\max }$ are the minimum and maximum oil droplet diameters, respectively, taken in this study as: $d_{\min }=1 \mu \mathrm{m}$ and $d_{\max }=320 \mu \mathrm{m}$, although Delvinge (1993) has shown that $d_{\max }$ depends on the 
magnitude of T.K.E., E, and oil viscosity. Most oil droplets in the experiments of Delvinge (1993) were found to have diameters in the range between 75 and $320 \mu \mathrm{m}$, with a slight tendency for shifting the median of droplet size distribution to small sizes with increasing turbulence duration. Other investigators, as Kolluru et al. (1995), Brovchenko et al. (2003), and Maderich and Brovchenko (2003), have argued that $d_{\max }$ depends on the T.K.E. dissipation rate, $\varepsilon$, and some of the physical properties of the oil. The values $d_{\min }, d_{\max }$ used in the literature range between 1 and $1000 \mu \mathrm{m}$.

The value $C_{d}(0)$, of surface volume concentration of oil particles with size $d$, maybe used now to

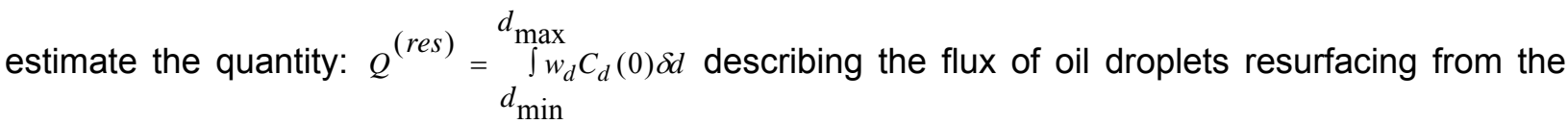
water column, whereas the total oil (volume) concentration, $C_{e}$ representing all droplet sizes, is expressed as: $C_{e}=\int_{d_{\min }}^{d_{\max }} C_{d} \delta d$.

Finally, taking into account the evaporation losses (per unit surface area) from the oil slick surface, a first order oil mass balance can be written down, vis.: $Q^{(h)}=-Q^{(\text {dis })}+Q^{(\text {res })}-Q^{(\text {evap })}$, that expresses the oil mass exchange between the slick and the water column and allows estimation of a uniform slick thickness, $h^{\circ} ; Q^{(h)}\left(=\rho_{0} h^{\circ}\right)$ represents the oil mass in the surface slick, $\rho_{o}$ being the oil density. An expression for the evaporation losses $Q^{(\text {evap) }}$, taking into account the oil properties and the wind speed, may be found in Papadimitrakis et al. (2005).

Tkalich (2006) and Tkalich and Chan (2002), by balancing the breaking wave energy and droplet buoyancy, have provided alternative and complementary expressions for estimating $C_{e}$, that may be useful in oil mixing parameterization. These expressions combine the oil properties and the wave breaking characteristics in a single "mixing factor- $\Lambda$ ", and are perhaps simpler than the previous calculations of $C_{e}$ in the oil mixing zone. Yet, the original Eqs. (1-3) provide the complete distribution of oil volume fraction $C_{e}$, throughout the water column and not only in the oil mixing zone of vertical extent $z_{m}$. According to these authors, the uniform mass concentration of oil droplets in the mixing zone, $\mathrm{C}_{\mathrm{em}}$, changes at a rate that depends on the surface slick characteristics, and particularly on the slick thickness $\mathrm{h}$. More specifically:

$$
\frac{d C_{e m}}{d t}=\frac{K}{z_{m}}\left(\Lambda \rho_{O} h^{O}-z_{m} C_{e m}\right) \quad ; \quad \frac{d h^{O}}{d t}=\frac{K}{\rho_{O}}\left(\Lambda \rho_{o} h^{o}-z_{m} C_{e m}\right) ; \quad C_{e m}=\rho_{o} C_{e}
$$

where: $\Lambda=\frac{\lambda_{\text {ow }}}{\lambda_{\text {wo }} B_{1}} ; \mathrm{K}=\left(\lambda_{\mathrm{ow}}+\lambda_{\mathrm{wo}}\right) \lambda_{\mathrm{wo}} \cdot \mathrm{B}_{1} /\left(\lambda_{\mathrm{ow}}+\lambda_{\mathrm{wo}} \cdot \mathrm{B}_{1}\right)\left(\right.$ in s $\left.^{-1}\right)$

$$
\lambda_{\text {ow }}=k_{b} \sigma_{o} \gamma H_{s} /\left(16 a L_{o w}\right)\left(\text { in s }^{-1}\right) ; \lambda_{w o}=w\left(r_{1}\right) / L_{w o} ; w(r)=k_{w} r^{p}
$$

$$
\mathrm{p}=2, \mathrm{k}_{\mathrm{w}}=2 \mathrm{~g}\left(1-\rho^{\prime}\right) / 9 \mathrm{v}_{\mathrm{w}} \text { if } \operatorname{Re} \leq 50 ; \text { otherwise } \mathrm{p}=0.5, \mathrm{k}_{\mathrm{w}}=\left[16 g\left(1-\rho^{\prime}\right) / 3\right]^{1 / 2} ; \operatorname{Re}=2 \mathrm{r} w_{d} / \mathrm{v}_{\mathrm{o}}
$$

$$
\mathrm{r}_{1}=0.5\left(r_{\max }^{p}+r_{c}^{p}\right)^{1 / p} \quad, \mathrm{w}\left(\mathrm{r}_{1}\right)=0.5 \mathrm{k}_{\mathrm{w}}\left(r_{\max }^{p}+r_{c}^{p}\right) \quad, \quad \mathrm{B}_{1}=\left(r_{\max }^{3-s}-r_{c}^{3-s}\right) /\left(r_{\max }^{3-s}-r_{\min }^{3-s}\right)
$$$$
\mathrm{s}=2.3 \pm 0.06,\left(\mathrm{r}_{\min } \approx 1 \mu \mathrm{m}, \mathrm{r}_{\max } \leq 1000 \mu \mathrm{m}\right), \mathrm{r}_{\mathrm{c}}=50 \mu \mathrm{m}, \quad r_{\max }=1818 \varepsilon^{-0.5} v_{O}^{0.34}
$$

$$
\gamma=10^{-5} \sigma_{o}\left(g \rho_{w} H_{s}^{2} / 16\right)^{0.25}
$$

The coefficient $k_{b}$ expresses the part of the dissipated (via breaking) wave energy spent to entrain oil droplets from the surface slick to the water column. All characteristic droplet radii, $r_{\text {char }}$ depend on various parameters, vis.: $r_{\text {char }}=\left(r_{\text {min }}, r_{c}, r_{1}\right)=r_{\text {char }}\left(\varepsilon, \sigma_{t}, v^{\prime}, \rho^{\prime}\right)$, where $\sigma_{t}$ is the oil-water surface tension $(\approx 0.01 \mathrm{~N} / \mathrm{m}), v^{\prime}=v_{O} / v_{W}, \rho^{\prime}=\rho_{O} / \rho_{W}$, and $v_{o}$ is the oil viscosity. $\mathrm{L}_{w o}$ is a vertical length 
scale in $(m)$ depending on oil buoyancy, the vertical components of current velocity and diffusion, and the breaking wave characteristics.

Denoting with $M_{s}$ and $M_{e}$ the mass of oil contained in the slick and in the oil mixing zone per unit surface area, respectively, we can now rewrite Eqs. (5) in terms of $M_{s}$ and $M_{e}$, namely: $\frac{d M_{e}}{d t}=K\left(\Lambda \cdot M_{s}-M_{e}\right) \quad ; \quad \frac{d M_{s}}{d t}=-K\left(\Lambda \cdot M_{s}-M_{e}\right)$

provided that $M_{s}=\rho_{0} h^{\circ} A$ and $M_{e}=\rho_{0} C_{e} z_{m} A$, where $A$ represents a unit area $\left(1 \mathrm{~m}^{2}\right)$, and that the total oil mass in the slick and in the water column $\left(M_{s}+M_{e}=M_{a}\right)$ remains constant. Evaporation losses maybe added to the above equation referring to $M_{s}$, in the form of: $d M_{s} / d t=-b M_{s}$, where $b$ is the

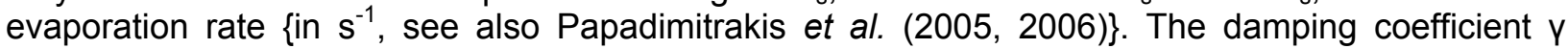
$(\approx 0.004)$ and the fraction $k_{b}(\approx 0.3-0.5)$ may also be determined experimentally, whereas $L_{o w}$ and $\mathrm{L}_{\mathrm{wo}}$ are introduced for maintaining correct units. According to Tkalich (2006), $\mathrm{L}_{\mathrm{ow}} \approx 1 \mathrm{~m}, \mathrm{~L}_{\mathrm{wo}} \approx 20 \mathrm{~m}$. The mixing factor $\Lambda$ can be related to the empirical oil mass entrainment rate proposed by Delvinge and Sweeney (1988), when the latter is converted into a dimensionless form, vis.: $\Lambda_{D S} \propto \frac{H_{S}^{1.14} V}{v_{O}}$, where $V$ is the volume of oil in all droplets within a unit volume of the oil mixing layer. Apparently: $V=\mathrm{C}_{\mathrm{e}} . \quad V=\int_{r_{\min }}^{r_{\max }} N(r) d v, \quad N(r)=\frac{(3-s) V}{4 \pi\left(r_{\max }^{3-s}-r_{\min }^{3-s}\right)} r^{-s},(s \neq 3), \quad \mathrm{u}=4 \pi r^{3} / 3$. The equivalent expressions of $\Lambda$ entering Eqs. (8) are: $\Lambda \propto \frac{\gamma_{S}{ }_{S}}{\sigma_{t}^{6}{ }_{t}{ }_{o}^{0.68} \rho_{\rho_{0}}^{0.75}}$ for $\mathrm{Re}<50$, and $\Lambda \propto \frac{{ }^{\gamma H}{ }_{S}}{\sigma_{t}^{0.3} v_{o}^{0.17} \rho_{o}^{0.75}}$ otherwise. Thus, $N / \Lambda_{\mathrm{DS}} \propto \mathrm{Y} \mathrm{H}_{S}^{-0.14} \sigma_{t}^{-\alpha^{\prime}} v_{O}^{\beta^{\prime}} \rho_{O}^{-0.75}$; where $\alpha^{\prime}=6, \beta^{\prime}=0.32$ for $\operatorname{Re}<50$, and $\alpha^{\prime}=$ $0.3, \beta^{\prime}=0.83$ otherwise.

The above Eqs. (5-8) allow estimation of $C_{e}$ (or $C_{e m}$ ), once more, and of the oil mass fractions $M_{e} / M_{a}, M_{s} / M_{a}$ as a function of mixing parameter $\Lambda$. Provided that the latter can be expressed as a function of the significant slope of the wave field (whose definition follows in section 2), it maybe possible to express the fraction $\mathrm{C}_{\mathrm{e}}$ as a function of the wave field characteristics. Due to the limiting space, however, we shall not elaborate any further on this matter.

\subsection{Water-in-oil emulsification}

Emulsification involves the dispersion of water droplets into the oil mass, found in the water column, converting oil into a very viscous, colloidal "chocolate mousse" with density approaching that of clean water. The initiation of mousse formation may depend on the amount of "natural" dispersants contained within the oil spilled on the sea surface. Emulsification is important for certain oils that have chemical constituents favoring the formation and stability of emulsified water. The rate of emulsification increases with increasing sea state and can be described by the following expression proposed by Mackay et al. (1979):

$\frac{d C_{2}}{d t}=K_{A}\left(1+U_{w}^{2}\right)\left(1-K_{B} C_{2}\right)$

where $\mathrm{C}_{2}$ is the fractional water content, within the dispersed oil, $1 / \mathrm{K}_{\mathrm{A}}$ is the final fractional water content $(0.8-0.85)$ and $\mathrm{K}_{\mathrm{B}}$ is an empirical coefficient $(\approx 1.43)$ which may depend on the wind speed $U_{w} . C_{2}$ affects the (volume) fraction $C_{e}$ of $R_{2}$ which is emulsified (Psaltaki, 2005).

\section{THE STOCHASTIC WAVE BREAKING MODEL}

According to Papadimitrakis and Psaltaki (2002), the fraction $\widetilde{\omega}$ of wave energy dissipated into turbulence by breaking, per unit area and average wave period, is given as: 


$$
\widetilde{\omega}=\frac{1}{\rho \mathrm{gh}^{2}} \int_{o}^{\infty} \int_{h_{0}}^{\infty} \rho \mathrm{g}\left(\mathrm{h}^{2}-\mathrm{h}_{\mathrm{O}}^{2}\right) \mathrm{p}(\mathrm{h}, \sigma) \mathrm{dhd} \sigma \quad ; \quad \overline{\mathrm{h}^{2}}=2 \mathrm{~m}_{0}
$$

where $p(h, \sigma)$ is the joint probability distribution of waves having amplitude, $h$, and frequency, $\sigma$, and $h_{\circ}$ is the limiting amplitude of the wave at frequency $\sigma$. In Papadimitrakis (2005), the author provided the following expression for $p(h, \sigma)$, vis.:

$$
\mathrm{p}(\mathrm{h}, \sigma)=\mathrm{a}_{\mathrm{y}} \mathrm{h}^{2} \exp \left(-\mathrm{b}_{\mathrm{y}} \mathrm{h}^{2}\right)
$$

where:

$$
\begin{aligned}
& \mathrm{a}_{\mathrm{y}}=\frac{4 \sigma^{3}}{\alpha^{2}(2 \pi)^{1 / 2} \mathrm{~m}_{0}^{3 / 2} \sigma_{0}^{4}} \times \frac{1}{\left(\theta^{2}-1\right)^{1 / 2}(\theta+1)} ; \mathrm{b}_{\mathrm{y}}=\frac{1}{2 \mathrm{~m}_{0}}\left\{1+\frac{\left\{1-\alpha^{-1}\left\{\sigma / \sigma_{0}\right\}^{2}\right\}^{2}}{\left(\theta^{2}-1\right) \rightarrow}\right\} \\
& \theta=\left(\mathrm{m}_{0} \mathrm{~m}_{4} / \mathrm{m}_{2}^{2}\right)^{\frac{1}{2}} ; \alpha=\left(\frac{\sigma_{\mathrm{p}}}{\sigma_{0}}\right)^{2} \times \frac{7}{\left\{2+\left[25+21\left(\theta^{2}-1\right)\right]^{\frac{1}{2}}\right\}}
\end{aligned}
$$

The subscript $p$ refers to the spectral peak; $\theta$ is the ratio of the expected number of wave extrema to that of zero crossings, per unit time. It is also a measure of the spectrum bandwidth; for an extremely narrow band case, $\theta=1.0$, whereas $\theta$ values close to 2.0 correspond to broad bandwidth spectra. The advantage of the above joint distribution is that it holds for both narrow- and broad-bandwidth spectra.

Expressions for $h_{0}$ can be obtained, for wind-induced waves in the absence and/or presence of swell, by utilizing the criterion set by Phillips and Banner (1974), properly modified to include surface drift effects (mainly of wind-induced origin). Now, upon integration of (6a), over all amplitudes exceeding $h_{0}$, an expression is obtained which provides the fractional wave energy losses by breaking per unit area per frequency, $\mathrm{P}_{\mathrm{L}}(\sigma)$, vis.:

$\mathrm{P}_{\mathrm{L}}(\sigma)=\frac{\mathrm{a}_{\mathrm{y}}}{4 \mathrm{~m}_{\mathrm{o}} \mathrm{b}_{\mathrm{y}}^{5 / 2}}\left\{\Gamma\left(5 / 2, \mathrm{~b}_{\mathrm{y}} \mathrm{h}_{\mathrm{o}}^{2}\right)-\mathrm{b}_{\mathrm{y}} \mathrm{h}_{\mathrm{o}}^{2} \Gamma\left(3 / 2, \mathrm{~b}_{\mathrm{y}} \mathrm{h}_{\mathrm{o}}^{2}\right)\right\}$

In terms of non-dimensional frequency $\Sigma\left\{=\sigma /\left(\alpha^{1 / 2} \sigma_{o}\right)\right\}$ and non-dimensional amplitude $\mathrm{H}\{=$ $\left.\mathrm{h} /\left(2 \mathrm{~m}_{\mathrm{o}}\right)^{1 / 2}\right\}, \mathrm{P}_{\mathrm{L}}(\sigma)$ maybe rewritten as:

$$
\begin{aligned}
& \mathrm{P}_{\mathrm{L}}(\Sigma)=4 \pi^{-1 / 2}(\theta+1)^{-1} \frac{\Sigma^{3}}{\left\{\theta^{2}-1+\left(\Sigma^{2}-1\right)^{2}\right\}^{5 / 2}}\left\{\left(\theta^{2}-1\right) \Gamma\left(5 / 2, \mathrm{x}_{\mathrm{O}}^{2}\right)-\left[\theta^{2}-1+\left(\Sigma^{2}-1\right)^{2}\right] \mathrm{H}_{\mathrm{O}}^{2} \Gamma\left(3 / 2, \mathrm{x}_{\mathrm{O}}^{2}\right)\right\} \\
& \text { where: } \quad \mathrm{x}_{\mathrm{o}}=\left[1+\frac{\left(\Sigma^{2}-1\right)^{2}}{\theta^{2}-1}\right]^{1 / 2} \mathrm{H}_{\mathrm{o}} \\
& H_{0}=\left(\begin{array}{ll}
4 \sqrt{2} \pi & \alpha_{1} \S
\end{array}\right)^{-1}\left(\frac{\Sigma_{p}}{\Sigma}\right)^{2} f \quad \text { for } \Sigma \leq \Sigma_{p} \\
& H_{0}=\left(\begin{array}{ll}
4 \sqrt{2} \pi & \alpha_{1} \S
\end{array}\right)^{-1}\left(\frac{\Sigma_{p}}{\Sigma}\right)^{2} f\left[1-a_{0}\left(\frac{c_{p}}{u_{*}}\right)^{-1}\left(\frac{\Sigma}{\Sigma_{p}}\right)\right]^{2} \text { for } \Sigma>\Sigma_{p} \\
& f=1+(h k)_{a v}^{2}+\frac{1}{2}(h k)_{a v}^{4}+\frac{1}{4}(h k)_{a v}^{6}-\frac{22}{45}(h k)_{a v}^{8}+\ldots . ;(h k)_{\mathrm{av}}=2 \sqrt{2} \pi \S \mathrm{H}_{\mathrm{av}}
\end{aligned}
$$




$$
\alpha_{\mathrm{O}}=\alpha_{\mathrm{OO}}-8 \pi^{2} \S^{2}\left(\frac{\mathrm{c}_{\mathrm{p}}}{\mathrm{u} *}\right) ; \S=\frac{m_{o}^{1 / 2} \sigma_{p}^{2}}{2 \pi g} ; \alpha_{o \mathrm{o}}=\varphi\left(\mathrm{u}_{*}\right), \alpha_{1}=1.2323
$$

$\mathrm{f}$ expresses a measure of non-linearity of the wave field; $\Gamma($,$) represents the incomplete Gamma$ function, $\mathrm{H}_{0}=h_{0} /\left(2 m_{0}\right)^{1 / 2}, \mathrm{H}_{\mathrm{av}}$ is the first moment of the normalized amplitude density, $\mathrm{u} *$ is the wind friction velocity, and $c_{p}$ is the phase velocity of the dominant wave at the spectral peak frequency (see also Papadimitrakis, 2005). In the presence of swell, and for frequencies $>\Sigma_{\text {cr }}$, Eq.(17b) is modified by replacing the expression inside the square bracket by: $\left[\left(1-m^{\prime}\right)^{2}-\left(1+2 m^{\prime}-\right.\right.$ $\left.\left.3 \mathrm{~m}^{\prime 2}\right) \mathrm{B}^{\prime}\right]$, in order to account for the short and long wave interactions; $\mathrm{m}^{\prime}=\alpha_{0}\left(\mathrm{u}_{*} / \mathrm{c}_{\mathrm{p}}\right)\left(\Sigma / \Sigma_{\mathrm{p}}\right)$, $\mathrm{B}^{\prime}$ is the swell slope and $\Sigma_{\mathrm{cr}}\left\{=\left[4 B^{\prime}\left(1-B^{\prime}\right)\right]^{-1} \Sigma_{\mathrm{p}}\right\}$ is a frequency above which the long and short wave interactions become important.

The fraction $\widetilde{\omega}$ maybe obtained now by integrating Eq.(11) over all positive frequencies, namely: $\widetilde{\omega}=\int_{O}^{\infty} \mathrm{P}_{\mathrm{L}}(\Sigma) \mathrm{d} \Sigma . \mathrm{F}_{\mathrm{wc}}$ may now be determined through the following relationships (Huang, 1986):

$F_{w C}=f_{w C} / T_{O} \quad, \quad f_{w C}=\frac{t_{1}}{T_{O}} \frac{\eta}{2\left(h^{2}\right)^{1 / 2}}, \quad \eta=\int_{h_{0}}^{\infty}\left(h-h_{0}\right) p(h) d h$

where $t_{1}$ is the average life duration of whitecaps that maybe taken as roughly equal to $T_{O}$. The amplitude density $p(h)$ can be obtained from the joint density $p(h, \sigma)$ upon integration over all positive frequencies. In terms of non-dimensional amplitude $H, p(H)$ is expressed as:

$$
\begin{aligned}
& p(H)=\frac{2}{\theta+1} F(B) H \exp \left(-H^{2}\right), F(B)=1+\operatorname{erf}\left(B^{-1}\right)+\frac{B}{\pi^{1 / 2}} \exp \left(-B^{-2}\right), \\
& B=\frac{\left(\theta^{2}-1\right)^{1 / 2}}{H}
\end{aligned}
$$

The present work focuses on the estimation of volume fraction $C_{e}$ (or $C_{e m}$ ), according to Eqs. (1-4), and on the analytic estimation of $D_{b a}$ and $F_{w c}$. The fraction $C_{2}$ related to the emulsified part of $R_{2}$ has been obtained with the aid of the numerical simulations of the oil spill fate and transport processes described in Psaltaki (2005), and to some extent in Papadimitrakis et al. (2005; 2006), and its distribution at various depths will be reported here.

\section{RESULTS-DISCUSSION}

Figures $1(a, b, c)$ show the variation of the fraction $\widetilde{\omega}$ as a function of significant slope, $\S$, in the presence or absence of swell, with or without a surface drift current. In the presence of swell, Figure 1 (c) shows the variation of $\widetilde{\omega}$ with $\S$ and the swell slope, $B^{\prime}$, as a parameter. Figure 2 shows the variation of whitecap coverage fraction, $F_{w c}$, as a function of $\S$.

In all of these Figures it is evident the steep rise of either $\widetilde{\omega}$ and/or $F_{w c}$ with $\S$, as the latter parameter increases beyond a value of about 0.02 . It is worth noting that $\S$ cannot grow indefinitely and its maximum value is somewhat less than the Stokes limit (0.05). It is also evident that the fraction $\widetilde{\omega}$ rises more abruptly in the presence of drift current (as it should due to premature breaking), whereas the value of the swell slope, $B^{\prime}$, affects $\widetilde{\omega}$ marginally. 


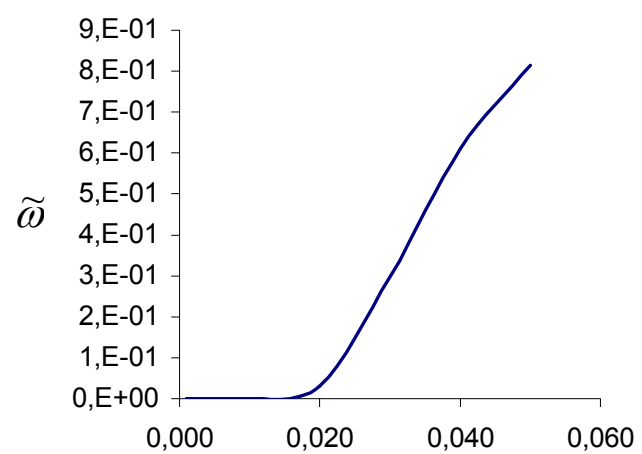

$\S$

Figure 1a. Variation of $\widetilde{\omega}$ as a function of $\S$ in the absence of swell and drift current

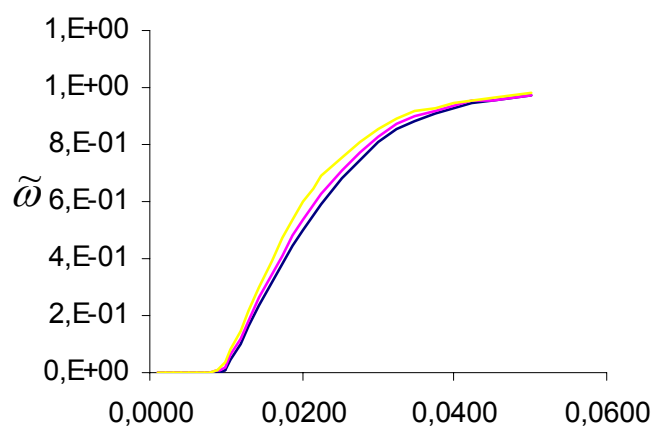

$\S$

Figure 1c. Variation of $\widetilde{\omega}$ as a function of $\S$ in the presence of drift current and of swell having various slopes $B^{\prime}: B^{\prime}=0.05$ (blue line), $B^{\prime}=0.15$ (red line), $B^{\prime}=0.30$ (yellow line)

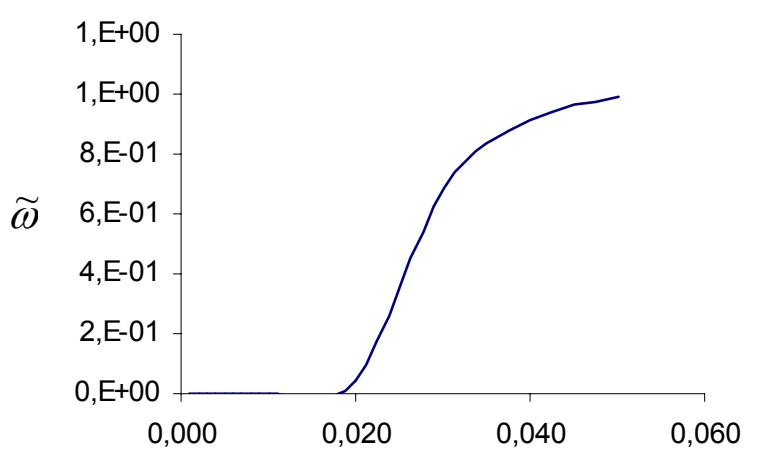

$\S$

Figure $1 b$. Variation of $\widetilde{\omega}$ as a function of $\S$ in the absence of swell and in the presence of drift current

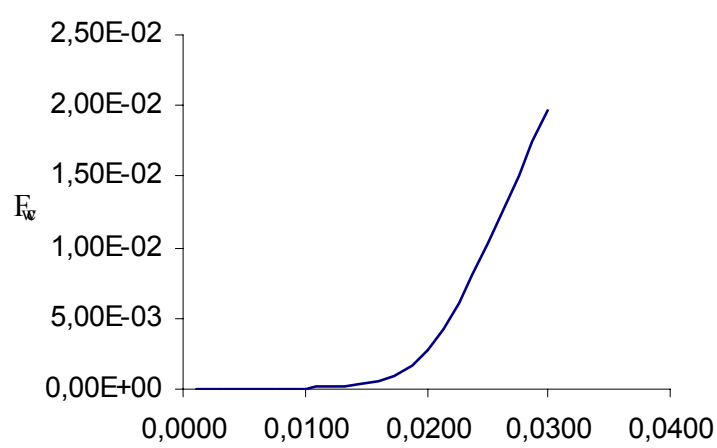

$\S$

Figure 2. Variation of $F_{w c}$ as a function of $\S$ in the absence of swell and drift current

Figure 3(a) shows the variation, with depth, of the average (over the slick area) value of the $R_{2}$ fraction of a slick formed in the Evoikos bay, 12 hours after the accident, corresponding to a hypothetical spill of $800 \mathrm{~m}^{3}$ of crude oil having a density of $800 \mathrm{~kg} \mathrm{~m}^{-3}$ and driven by a Northwestern wind $U_{w}=10 \mathrm{~m} \mathrm{~s}^{-1}$. The accident occurred at a hypothetical location $800 \mathrm{~m}$ from Eretria, a little town in Evoikos bay. The graph shows a change from a maximum $R_{2}$ value of $2.5 \times 10^{-6}$, at the surface, to a value of $1.5 \times 10^{-6}$ at the $20 \mathrm{~m}$ depth. This $R_{2}$ profile with depth gives an idea of the vertical dispersion developed in the water column of the simulated area, considering the weak circulation found in the area. Simulations with different oil densities show that the fraction $R_{2}$ increases with increasing oil density (at the sea surface at least). The $R_{2}$ depth profile shown in Figure 3(b), corresponds to another hypothetical spill that has occurred at a location $3 \mathrm{~km}$ away from the eastern corner of the Karava area (of Lesvos island), 18 hours after the spill accident. From these two $\mathrm{R}_{2}$ graphs and similar ones found from other simulations of hypothetical spills of various initial sizes, occurring at various distances from the nearby shores, it was found that (at the same depth) the $R_{2}$ fraction decreases with increasing distance from the (corresponding) shore and simulation time. It was also found that the $R_{2}$ profiles become less steep with depth, as the original spill location approaches the shore. 
Figure 3(c) shows a typical vertical distribution of the volume fraction $\mathrm{C}_{\mathrm{e}}$, under a Northwestern wind of $8 \mathrm{~m} \mathrm{~s}^{-1}$. The water depth is $50 \mathrm{~m}$. The volume fractions, at the surface and at 10, 20, 30, 40 and $50 \mathrm{~m}$ depths, correspond to 72 hours of simulation time. Figure $3(\mathrm{~d})$ shows a typical $\mathrm{C}_{\mathrm{em}}$ vertical distribution, corresponding to certain wind-wave and bathymetry conditions that represent the experiments conducted by Delvinge (1993) for appraising the oil droplet mass flux from the surface slick into the water column caused by natural dispersion (i.e., $U_{w}=17.5 \mathrm{~m} \mathrm{~s}^{-1}, \mathrm{H}_{\mathrm{s}}=1.6 \mathrm{~m}, \mathrm{~T}_{\mathrm{o}}=4.8 \mathrm{~s}$, water depth $=4.7 \mathrm{~m}$ ). In the same Figure we also show present results produced by Eq.(5).

In another simulation run, a spill with an initial volume of $800 \mathrm{~m}^{3}$ of crude oil having a density of 860 $\mathrm{kg} \mathrm{m}^{-3}$, occurs at a location $800 \mathrm{~m}$ from Eretria, a little town in Evoikos bay. The simulation considers the transport and fate of the spilled oil under the action of the tidal currents, present in the area, and a Northwestern wind $U_{w}=10 \mathrm{~m} \mathrm{~s}^{-1}$. Figure 4(a) shows the distribution of the volume fraction $\mathrm{C}_{2}$ of the water-in oil emulsion (the so-called $3^{\text {nd }}$ phase) formed at the sea surface (and throughout the water column), 24 hours after the initiation of the (numerical) experiment. Figure 4(b) shows similar results, 5 hours after the initiation of a numerical experiment regarding another spill accident, when $800 \mathrm{~m}^{3}$ of oil with density $830 \mathrm{~kg} \mathrm{~m}^{-3}$ were spilled at a location $200 \mathrm{~m}$ away from the upper western corner of Prasologos, a small island of extreme beauty, a shallow bird habitat included in the NATURA network. Figure 4(c) shows the distribution of the water-in-oil emulsion fraction $\mathrm{C}_{2}(=\mathrm{PTO})$ of a three component oil with densities 700,800 and $900 \mathrm{~kg} \mathrm{~m}^{-3}$, at the sea surface of Evoikos bay, under the action of a $10 \mathrm{~m} \mathrm{~s}^{-1}$ Northwestern wind, 12 hours after the initiation of the experiment. Now the simulation was performed using the algebraic slip model of PHOENICS CFD code. Figure 4(d) presents in two graphs the water fraction uptake by the oil as a function of time, one depicting the results predicted by the SINTEF (OWM) model and the other our results predicted by Eq.(9).

Finally, Figure 5 shows the mass balance of a spill, at the sea surface, 28 days after the initiation of numerical experiment. The spill has an initial volume of $800 \mathrm{~m}^{3}$ of crude oil with density of $800 \mathrm{~kg} \mathrm{~m}^{-3}$ and is supposed to occur at a distance $3 \mathrm{~km}$ from the eastern corner of Karava shore, in the island of Lesvos. The simulation run lasted 28 days in order to also study the effects of biodegradation. Thus, Figure 5 shows the percentages of evaporation, biodegradation and the fraction representing the combined processes of dissolution, photo-oxidation, emulsification, natural dispersion in the water column and sedimentation. As seen, roughly $34 \%$ of the oil is lost through evaporation, $12 \%$ is lost by biodegradation, and $51 \%$ is lost during the activation of the above mentioned processes. The oil fraction lost by biodegradation is in agreement with similar literature findings (Del' Arco and De Franka, 1999). Figure 5(c) plots, in two graphs, the mass balance of a spill, 72 hours after the initiation of the numerical experiment. The upper graph depicts the mass balance predicted by the SINTEF (OWM) model, whereas the lower graph depicts the corresponding balance under similar meteorological and oceanographic conditions.

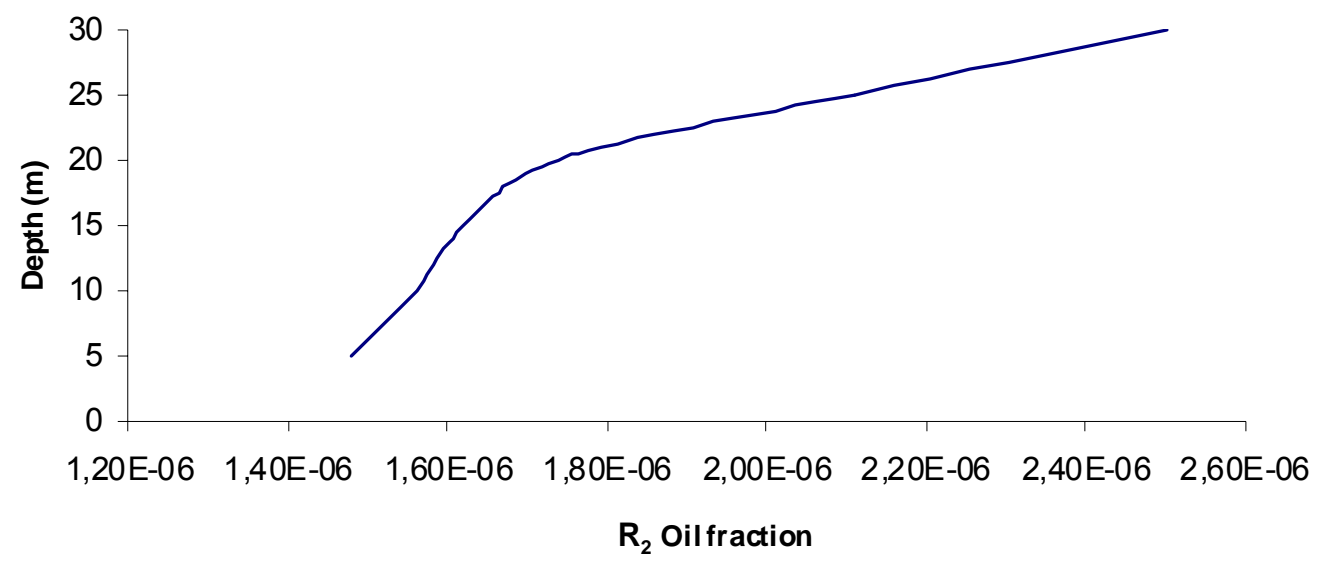

Figure 3a. Average $\mathrm{R}_{2}$ fraction distribution with depth in the Evoikos bay, 12 hours after the initiation of numerical experiment. Sea bottom is placed at $z=0(\mathrm{~m})$ 


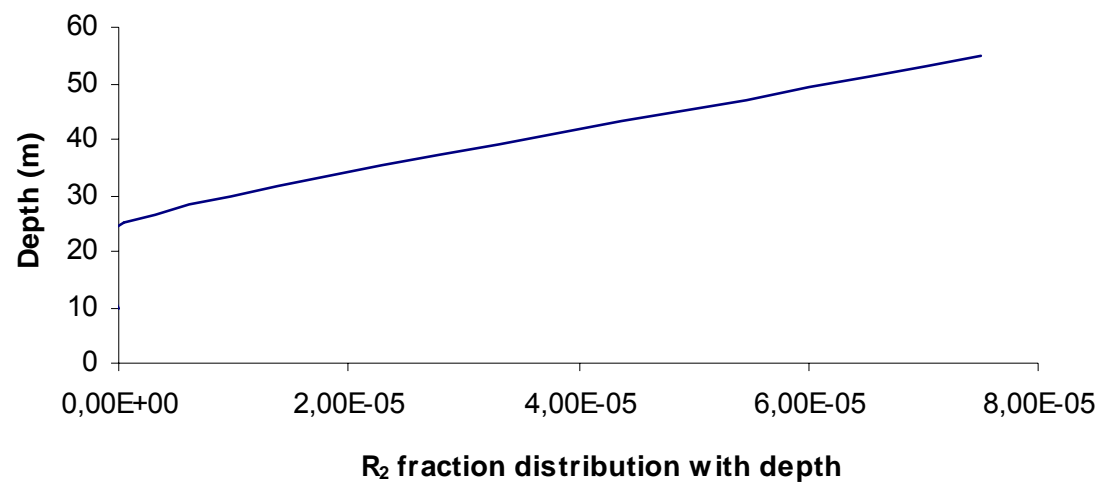

Figure $3 b$. Average $\mathrm{R}_{2}$ fraction distribution with depth in the Karava area, 18 hours after the initiation of numerical experiment. Rest as in Figure 3a

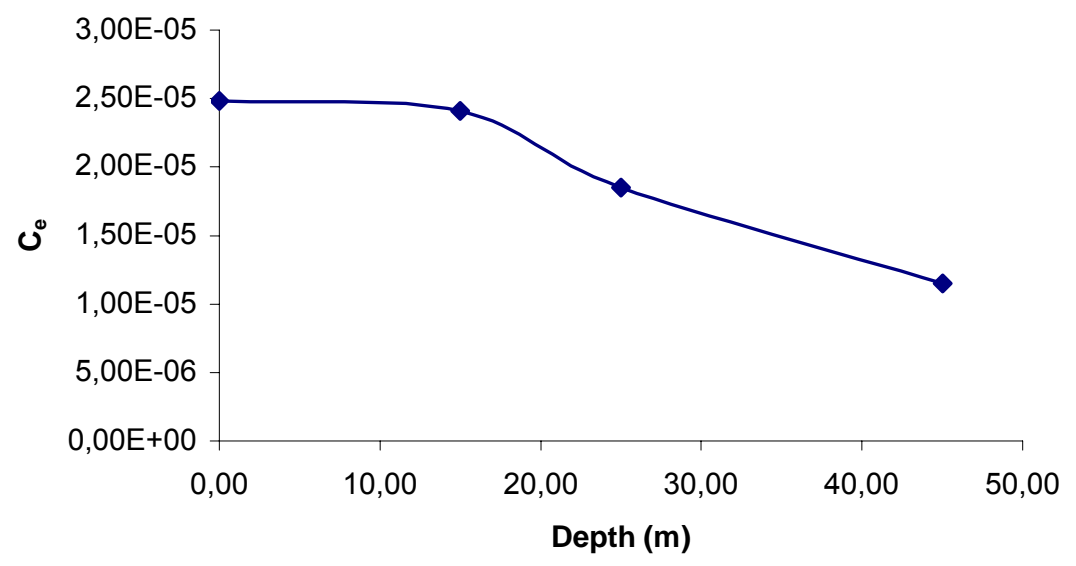

Figure 3c. Typical $C_{e}$ distribution with depth. Sea surface is placed at $z=0(\mathrm{~m})$

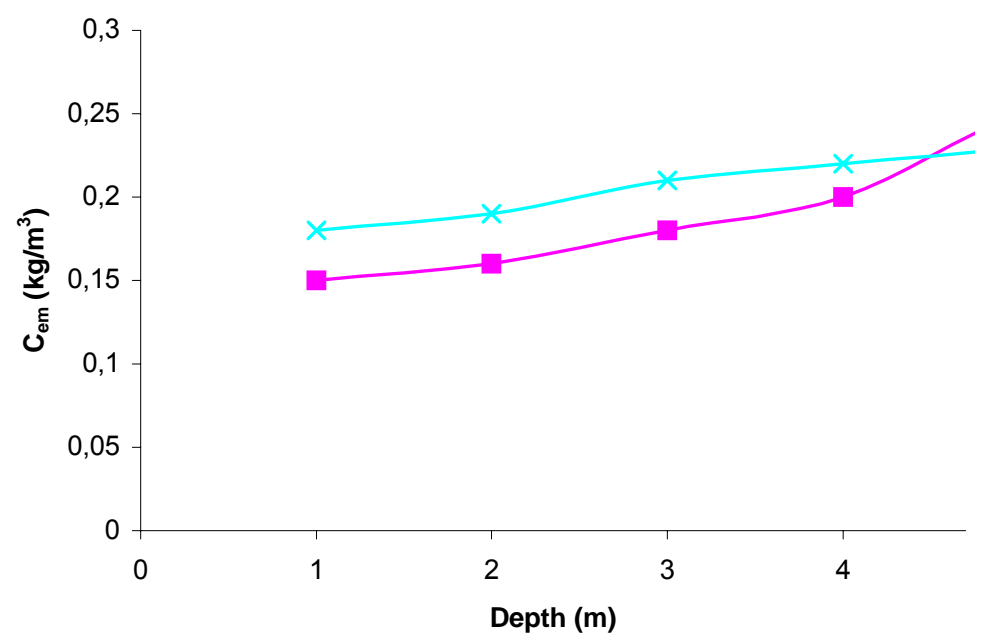

Figure 3d. Typical $\mathrm{C}_{\mathrm{em}}$ vertical distribution in the oil mixing zone. Purple line represents results obtained by Delvinge and Sweeney (1988). Green line represents current results 


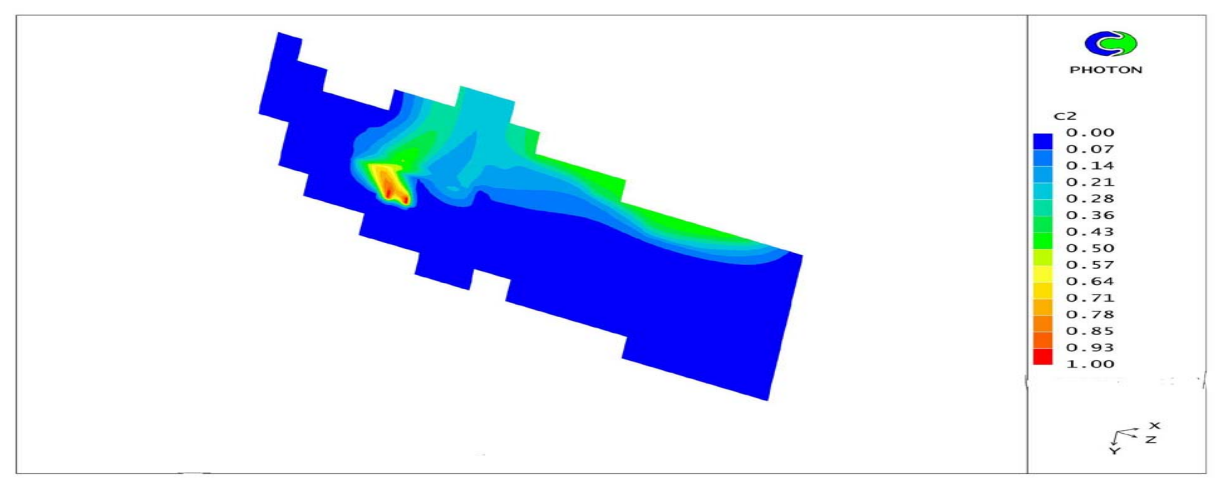

Figure $4 a . \mathrm{C}_{2}$ water-in-oil emulsion distribution of a single component oil, at the sea surface near Eretria at the Evoikos bay, 24 hours after the initiation of the numerical experiment

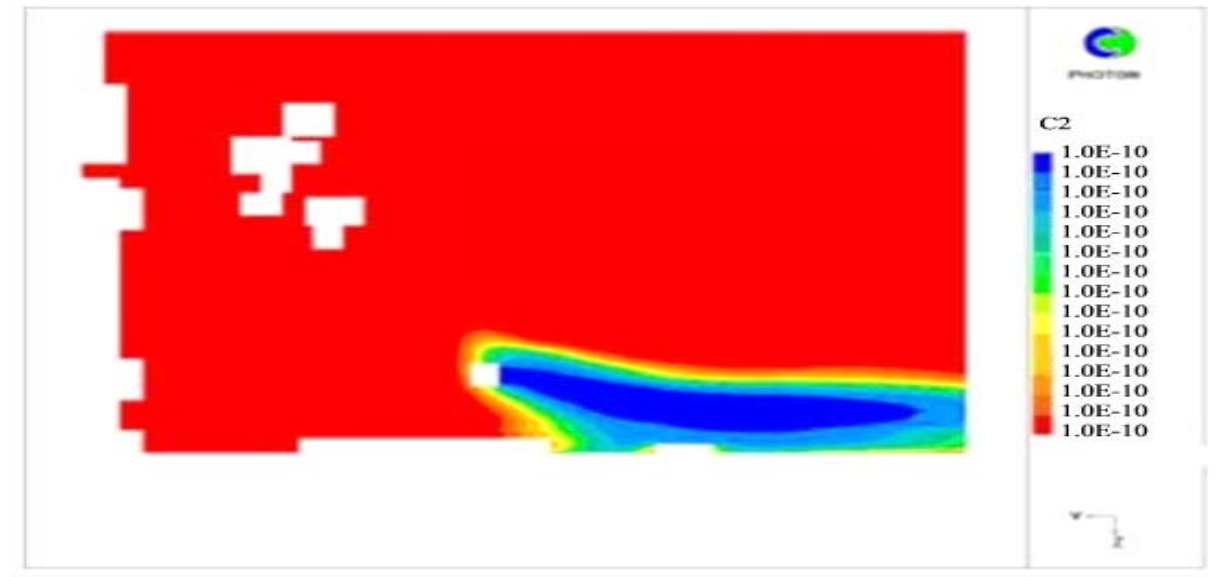

Figure $4 b . C_{2}$ water-in-oil emulsion distribution of a single component oil, at the sea surface near Prasologos island, 5 hours after the initiation of the numerical experiment

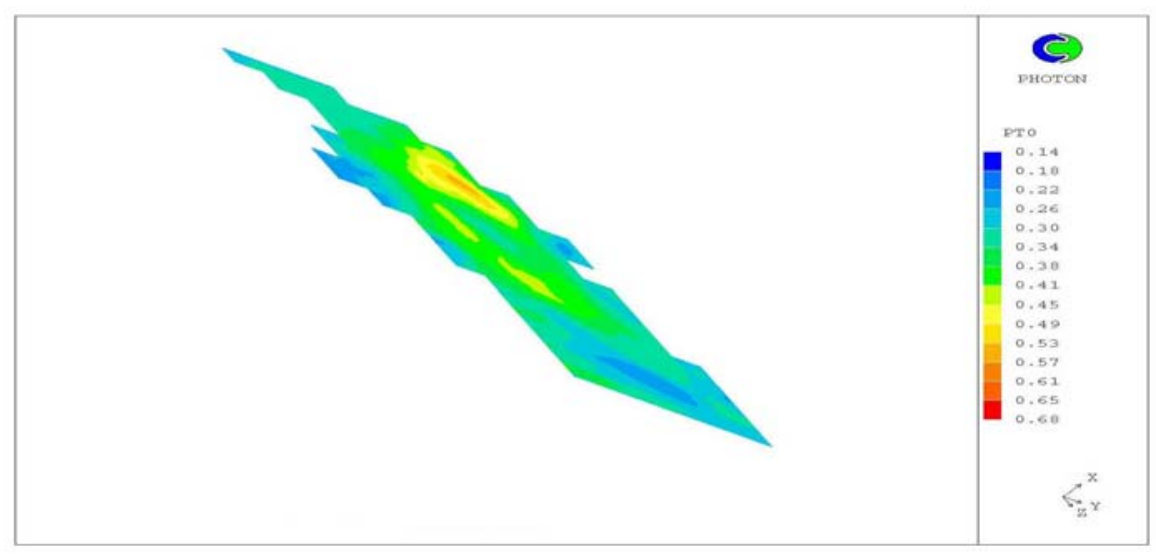

Figure $4 c . \mathrm{C}_{2}$ water-in-oil emulsion distribution of a three component oil, at the sea surface of Evoikos bay, 12 hours after the initiation of the numerical experiment 
(a)

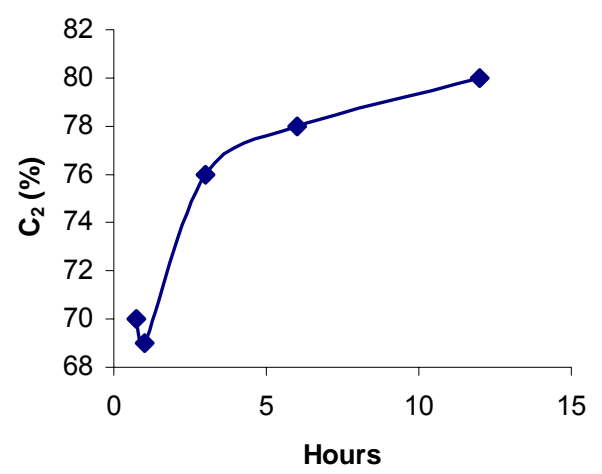

(b)

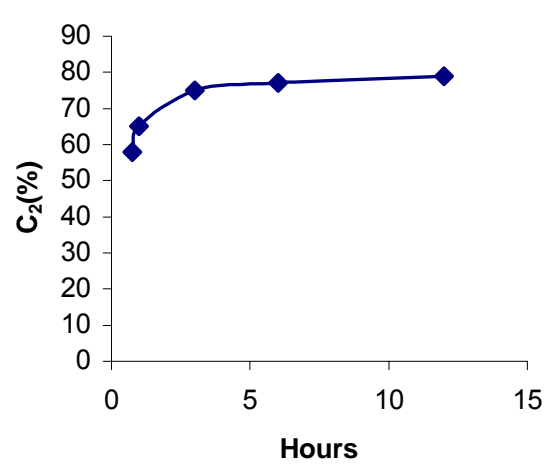

Figure $4 d$. Variation of volume fraction $\mathrm{C}_{2}$ with time: (a) SINTEF Results, (b) present results

(a)

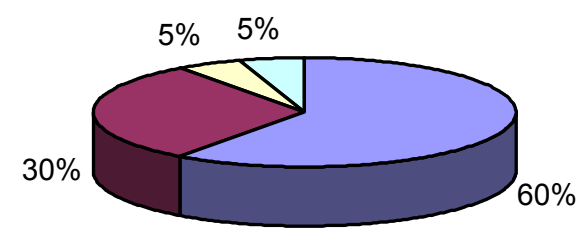

口Natural Dispersion

口Evaporation

口Biodegradation

口Remaining

(b)

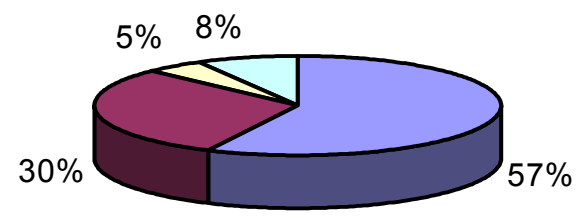

$\square$ Natural Dispersion

口Evaporation

口Biodegradation

口Remaining

Figure 5. Typical mass balance of an oil spill at the sea surface 72 hours after the initiation of numerical experiment: (a) SINTEF (OWM) results, (b) present results

\section{CONCLUDING REMARKS}

As seen from Figures $1(a, b, c)$, the fraction $\widetilde{\omega}$ takes on values from zero to about unity, under the various sea state conditions. Only when $\widetilde{\omega}$ is roughly equal to $3 \times 10^{-3}$, the ratio $D_{b e}^{a} / D_{b e}^{e}$ becomes about unity. We may, therefore, conclude that the formula suggested by Delvinge (1993) for estimating wave energy losses by breaking, may under- or overestimate these losses depending on the se state. 


\section{REFERENCES}

Brovchenko I., Kuschan A., Maderich V., Shliakhtun M., Koshebutsky V. and Zheleznyak M. (2003), Model for oil spill simulation in the Baltic sea. MEDOSC, 3nd Int. Conf. on: Oil Spills, Oil Pollution and Remediation, 16-18 Sept. 2003, Instambul, Turkey, 101-112.

Del' Arco J.P. and De Franka F.P. (1999), Biodegradation of crude oil in sandy sediments, Int. Biodeterioration and Biodegradation, 44(2-3), 87-92.

Delvinge G.A.L. and Sweeeney C.E. (1988), Natural dispersion of oil, Oil \& Chem. Poll., 4, 281-310.

Delvinge G.A.L. (1993), Natural dispersion of oil by different sources of turbulence, In: Proc. 1993 oil spill Conf., Atlanta, GA, USA, 415-419.

Gender S. (1988), In situ detection and tracking of oil in the water column, Oil Chem. Poll., 4, 113-126.

Huang N. (1986), An estimate of the influence of breaking waves on the dynamics of the upper ocean. Wave Dynamics and Radio Probing, Phillips, O.M. and Hasselman, K. (Eds.), 295-313.

Kolluru V.S., Spaulding M.L. and Anderson E.L. (1995), A three-dimensional subsurface oil dispersion model using a particle based approach, Proc. $17^{\text {th }}$ AMOP Seminar, Envir. Canada, Ottawa, Canada, 867-894.

Korotenko K.A., Mamedov R.M. and Mooers C.N.K. (2000), Prediction of the dispersal of oil transport in the Caspian sea resulting from a continuous release, Spill Sci. \& Techn. Bull., 6(5-6), 323-339.

Li M. and Garret C. (1998), The relation between oil droplet size and upper ocean turbulence, Marine Poll. Bull., 36, 961-970.

Mackay D., Bouist I., Mascarenhas R. and Paterson S. (1979), Oil spill processes and models. Publication EE-88, Report for Fisheries, Envir. Canada, Ottawa, Ontario, pp. 120.

Maderich V.S. and Brovchenko I.A. (2003), Effect of the wind-wave breaking on the structure of surface turbulent layer in the ocean, Applied Hydromechanics, 5(77), No. 3.

Papadimitrakis Y.A. (2005), On the probability of wave breaking in deep waters, Deep-Sea Res. II, 52, 1246-1269.

Papadimitrakis I.A. and Psaltaki M. (2002), Estimation of natural oil dispersion in the water column due to breaking waves in deep water (in Greek). $2^{\text {nd }}$ Nat. Conf. on: Management and Improvement of Coastal Zones, Athens, Greece, November 25-28, 117-127.

Papadimitrakis J., Psaltaki M., Christolis M. and Markatos N.C. (2006), Simulating the fate of an oil spill near coastal zones: The case of a spill (from a power plant) at the Greek island of Lesvos, Environmental Modelling \& Software, 21, 170-177.

Papadimitrakis J., Psaltaki M., Christolis M. and Markatos N. (2005), Three-dimensional oil spill modelling for coastal waters, J. Marine Env. Eng., 7, 249-260.

Phillips O.M. and Banner M.L. (1974), Wave breaking in the presence of wind drift and swell, J. Fluid Mech., 66, 625-640.

Psaltaki M. (2005), Simulation of oil spill behavior in the marine environment. Ph.D. Thesis (in Greek). NTUA, School of Chemical Engineering, CFD Unit, Athens, Greece.

Reed M., Gundlach E. and Kana T.A. (1989), Coastal zone spill model: development and sensitivity studies, Oil Chem. Poll., 5, 441-449.

Reed M., Johansen O., Brandvik J., Daling S., Lewis A., Fiocco R., Mackay D., Prentki R. (1999), Oil spill modeling toward the close of the 20th century: overview of the state of the art, Spill Sci. Technol. Bull., 5(1), 3-16.

Spaulding M.L. (1995), Oil spill and fate modelling: State-of-art review, $2^{\text {nd }}$ Int. Oil Res. Develop. Forum, 23-26 May, IMO, London, UK.

Spaulding, M.L. (1988), A state-of-art review of oil spill trajectory and fate modeling, Oil Chem. Poll., 4, 39-55.

Spaulding M.L., Sila S.B., Reed M., Lorda E., Walker H.Isaji, T, Swanson J. and Anderson E. (1988), Assessing the impact of oil spills on a commercial fishery. Final Report to Mineral Management Service. Contract No. AA851-CTO-75. NTIS No. PB83-149104.

Tkalich P. (2006), A CFD solution of oil spill problems, Environmental Modelling \& Software, 21, 271-282.

Tkalich P. and Chan E.S. (2002), Vertical mixing of oil droplets by breaking waves, Marine Poll. Bull., 44, 1219-1229. 